\title{
Inequality of opportunities in the labor market: evidence from life in transition surveys in Europe and Central Asia
}

\author{
Ana Abras,, Alejandro Hoyos, Ambar Narayan and Sailesh Tiwari
}

\author{
* Correspondence: analuisaabras@ \\ yahoo.com.br \\ Poverty Reduction and Equity \\ Department (PRMPR), World Bank, \\ 1818 Pennsylvania Avenue, \\ Washington, DC, USA
}

\begin{abstract}
In this paper we quantify inequality of opportunity in labor market outcomes in Europe and Central Asia using the Human Opportunity Index (HOI) methodology. Using data from the 2006 Life in Transition Survey we also compare $\mathrm{HOl}$-based measures of inequality with expenditure-based measures and examine the extent to which these measures resonate with perceptions of life satisfaction and fairness. Findings show substantial inequality of opportunity in employment status and large variations across countries. Correlations between measures and perceptions of inequality suggest that inequality between groups as opposed to overall inequality has stronger association with perceptions of fairness in society.
\end{abstract}

JEL: 011,012

Keywords: Inequality of opportunity; Inequality indexes; Labor markets in transition economies

\section{Introduction}

The issue of inequality currently dominates the discourse on political economy across the world. It is estimated that over a third of all countries in the world experienced some form of social and political strife in the last one year. While the reasons behind each of these expressions of anger, frustration or dissent were no doubt diverse, some of the more significant movements such as the los Indignados movement in Spain, the Arab Spring and the Occupy protests across major cities of the United States appear to have a common theme: perceptions of rising inequality, diminishing opportunity for economic mobility (jobs) and the widespread inability or unwillingness on the part of the incumbents in power to do anything about it through appropriate public policy.

Political and ideological differences generally make reaching a consensus on how to address inequality of outcomes such as income extremely difficult. But the idea that the playing field should be leveled and everybody should at least have a fair shot at becoming "successful" by any metric society deems appropriate usually has universal appeal. This concept of the equality of opportunity can have a lot of policy traction, but requires a measure or a set of measures that can provide a practical way of tracking a country or society's progress towards equalizing opportunities for all ${ }^{1}$.

In the last decade, a substantial progress has been made on the measurement of inequality of opportunities. John Roemer's work in 1993 and 1998 to formalize the equality of opportunity principle remains foundational to this literature. The World

(C) 2013 Abras et al.; licensee Springer. This is an Open Access article distributed under the terms of the Creative Commons Attribution License (http://creativecommons.org/licenses/by/2.0), which permits unrestricted use, distribution, and reproduction in any medium, provided the original work is properly cited. 
Bank's 2006 World Development Report, Equity and Development, provided the necessary policy salience by arguing that inequality of opportunity, both within and among nations, results in wasted human potential and weakens prospects for overall prosperity. The result has been a proliferation of approaches to measure inequality of opportunity using a variety of definitions. Of the two primary approaches, the first is often based on observed income (or its proxies, like consumption) ${ }^{2}$ The second, also known as the human opportunities index (HOI henceforth) approach, focuses more on children and considers the degree to which access to basic services such as quality schooling, health care and household and infrastructure amenities are equitable. Under both approaches, equality of opportunity is measured by the extent to which the measured outcomes or access variables are orthogonal to circumstances or characteristics an individual cannot be held accountable for.

In this paper, we use the HOI methodology to analyze inequality of opportunity in the labor market for working age adults. The ability of these individuals to access labor markets through jobs that befit the acquired human capital irrespective of their circumstances is a critical determinant of economic mobility and reduction in inequality in the long-run. So the key question we ask is the following: to what extent do an individual's ability to access a labor market opportunity (e.g., a job) depend on circumstances that he/she is born to and has no control over (e.g. gender, religion, race, parental background and place of birth) versus characteristics such as education and age. Building upon previous work on inequality of opportunity, we construct measures of inequality, decompositions of these measures, and provide cross-country comparisons.

In addition to the standard application of the HOI methodology to labor market outcomes, we also conduct a variety of supplementary exercises broadly in the spirit of validating this measure. First, we consider the extent to which alternative measures of inequality used earlier in the literature, such as the Theil index applied to continuous outcomes such as household expenditures (Ferreira et al., 2011), relate to measured inequality of opportunity in labor markets. Second, we examine the extent to which our measures of inequality of opportunity resonate with individual perceptions of life satisfaction and fairness. The underlying hypothesis is that if our indices are capturing what we intend for them to, they should be consistent with individual concerns about equality and fair play in the marketplace. Testing hypotheses on perceptions (of fairness and subjective well being) against measured inequality is a research agenda in itself; our foray into this area should be regarded simply as an exploratory attempt to determine whether our measures of inequality of opportunity in the labor market relate sensibly to these perceptions. To the best of our knowledge, this is the first attempt in the literature to quantify inequality of opportunity to labor market outcomes in a discrete setting (where the outcome variables are binary) and validate the measured inequality with perceptions of fairness and life-satisfaction.

We face some key methodological challenges. While it is possible to argue convincingly that the circumstances we regard as being beyond one's control (such as location) are truly immutable for children and young adults, the same cannot be said for working age adults. For example, a job seeker in particular region could actively exercise the choice of moving to the neighboring region, or the nearest urban center to look for work. What constitutes opportunities in the labor market is not clear-cut. For one, the observed outcome of an individual holding a job is an equilibrium phenomenon; it conveys no 
information about the individual's decision or preferences. For example, we cannot distinguish between an individual not having a job because none is available from one who is waiting for a better job ("queuing"), or between a worker who is at his job because s/he is satisfied from another who may be working simply because there is no alternative.

We attempt to overcome some of these methodological challenges in this paper. We use data from the 2006 round of the Life in Transition Survey (LiTS). The LiTS is a survey in 27 Europe and Central Asia (ECA) countries, Turkey and Mongolia, and collects information on the experience of transition since 1989. Importantly for us, it also contains detailed information on labor market status and family background of respondents. With the information available from the surveys, we (a) define observed outcomes in the labor market such that they reflect opportunities among a subset of the population, and; (b) identify the extent to which circumstances matter for the likelihood of having a particular opportunity. The choice of data from the LiTS is ideal because it is a homogeneous instrument across countries and contains all necessary information for the analysis. In addition, the issue of inequality of opportunity in general and the inequality of opportunity in the labor markets in particular, is highly pertinent for the countries in this region given their recent history of economic transition. The rest of the paper is organized as follows. Section 2 lays out the basic HOI framework and discusses the way in which we adapt this methodology for analysis of opportunities in the labor market. Section 3 presents our first set of results. Section 4 presents the results from comparing the measured inequality of opportunity countries against alternative measures of inequality, perceptions of fairness and life satisfaction. Section 5 summarizes the key results and concludes.

\section{Applying the HOl framework to labor market opportunities}

\subsection{Equality of opportunity and the HOI framework}

While social scientists and philosophers before the 1970s dealt mostly with the fairness of outcomes, the work by Rawls (1971) and Nozick (1974) brought to the forefront the question of fairness of process. Dworkin (1981)) and Arneson $(1989,1990)$ built on this work, dealing respectively with equality of resources and equality of opportunity for welfare. Cohen (1989) proposed equality in "access to advantage". Sen $(1979,1985)$ argued for an equitable distribution of "capabilities," which refer to sets of functionings effectively available for a person to choose from, so that they can pursue "life plans" they have reason to value 3 . Roemer characterizes their proposals as attempts "to equalize opportunities, rather than outcomes: for Rawls and Dworkin, primary goods and resources, respectively, are the wherewithal with which people carry out projects that lead to outcomes that have value to them; for Sen, the capabilities to function in various ways are the prerequisites for what individuals make of themselves; and Cohen's "access" is similar to Arneson's straightforward "opportunity" (Roemer, 1993). In his work published in 1993 and 1998, Roemer formalized an equality of opportunity principle, arguing that policy should work to equalize opportunities independent of circumstances and outcomes should depend only on effort.

Roemer (1998) distinguishes between five key concepts. Objective is the goal that equal opportunities are expected to achieve. Circumstances are the attributes of the environment of the individual (either social, genetic or biological) that affect the achievement of the 
objective, but that are beyond the control of the individual and for which society does not regard him or her responsible. Effort refers to individual behaviors and decisions that together with circumstances determine the level of objective accomplished. Instrument refers to the policy -typically the provision of resources- used to equalize opportunities. Type is the set of individuals all of whom have the same circumstances (also referred to as "circumstance groups" in some literature). Equality of opportunity exists when an objective or opportunity is achieved across same levels of effort across different circumstances groups or types.

The empirical literature on equality of opportunities that followed has taken several routes. One strand of work has used either parametric or nonparametric techniques to assess the impact of circumstances on some specific wellbeing objective or focused on the problem of measurement of the extent of (in) equality of opportunities in a given country or region. Examples of some empirical applications are (2003) and Bourguignon et al. (2007). Both of these papers analyze the effect that several circumstances (father's and mother's education, father's schooling, race and region of birth) and specific effort variables (such as own education, labor market status and migration as opposed to an undefined residual) on wage earnings differentials in Brazil.

Another strand of work - while remaining rooted in Roemer's concepts - has operationalized inequality of opportunity in different ways. Van der Gaer (1993), Ooghe et al. (2007), Hild and Voorhoeve (2004), and Cogneau and Mesplé Somps (2008) regard the dependence of the distribution of expected earnings on social origins to be a measure of inequality of opportunities. This body of work generally entails the estimation of the conditional expectations of earnings or consumption from the distribution of average income across several socio-economic categories and performing tests of stochastic dominance. Opportunities are regarded to be more equally distributed if the distribution of earnings or income conditional on social origins cannot be ranked according to the stochastic dominance criteria. (e.g. Lefranc et al. 2008.

In this paper we draw from the Human Opportunity Index (HOI) framework (see Barros et al., 2009, 2010). Developed by researchers at the World Bank in collaboration with external researchers, the HOI has been primarily motivated and used as an intuitive measure of a society's progress toward equitable provision of opportunities for all children. The HOI methodology takes into account the extent to which personal "circumstances" for which a child cannot be held accountable - say, location, gender, household composition or parental wealth - affect his/her probability of accessing basic services that are necessary to succeed in life, like timely education, vaccination, running water, electricity or connection to internet. The measure is the coverage rate of a particular service, discounted by a factor that takes into account how equitably the available services are distributed among types. The construction of HOI involves aggregating circumstance-specific coverage rates in a scalar measure that increases with overall coverage and decreases with the differences in coverage among groups with different sets of circumstances. More formally, HOI $(H)$ for a particular opportunity is the average coverage rate of access $\bar{C}$ multiplied by a penalty factor that is equal to 1 if the opportunities are equitably distributed. Specifically,

$$
H=\bar{C}(1-D)
$$


Where $D$ is the index of dissimilarity (D-index hereafter) that is equal to zero if access to the opportunity is independent of the circumstances, in which case HOI is equal to the average coverage rate. The D-index is often interpreted as the share of the total number of opportunities that needs to be reallocated between types ${ }^{4}$ to ensure equality of opportunities. It is computed as follows:

$$
D=\frac{1}{2 \bar{C}} \sum_{k=1}^{m} \alpha_{k}\left|\bar{C}-C_{k}\right|
$$

Here $k$ denotes a type or circumstance-group; $C_{k}$ the specific coverage rate of group $k$; $\alpha_{k}$ the share of group $k$ in total population of children; and $m$ the number of disjoint circumstance groups. $D$ is equal to zero when $\bar{C}=C_{k}$ for all $k$ types, in which case HOI is equal to the coverage rate, $\bar{C}$ It can be shown that $D$ is equal to the share of total opportunities that are "misallocated" in favor of (against) types that have coverage rates higher (lower) than $\bar{C}^{5}$.

It is important to note that the D-Index thus calculated is a function of the set of circumstances chosen for the analysis. Given that it is often impossible to identify and observe in the data all relevant circumstances for a given society, this raises a question as to the extent to which the measure is truly capturing inequality of opportunity. This concern, however, is mitigated by an important property: if additional circumstances are added to a particular set based on which the D-Index has been calculated, its value can only go up. This follows from the intuition that D-Index is a measure of betweengroup inequality and as the number of circumstance-groups increases, so will inequality between groups. This implies that the computed D-index serves as a lower bound to the "actual" inequality where all circumstances of interest could be included in the analysis ${ }^{6}$.

In practical terms, computing the HOI consists of running a logistic regression model to estimate the relationship between access to a particular opportunity and circumstances of the child, on the full sample for whom the HOI measure will be constructed. The estimated coefficients of the regression are used to obtain for each individual predicted probability of access to the opportunity; which is then used to estimate the coverage rate, inequality and HOI.

\subsection{Measuring inequality of opportunity in the labor market}

In order to measure inequality of opportunity in the labor market, we first estimate the extent of inequality (in the labor market) between groups. Unlike the case of usual HOI applications, these groups are characterized by circumstances as well as characteristics like education and age of the individual, which matter greatly for access to a labor market opportunity (like having a job) ${ }^{7}$. Thus the D-Index computed in this manner with both circumstances and characteristics reflects the overall level of inequality in the labor market, while the share of the overall inequality attributable only to circumstances can be interpreted as inequality of opportunity. In practical terms, between-group inequality (D-Index) is estimated by running a logistic regression model to estimate the relationship between access to a particular employment opportunity and circumstances as well as characteristics (education and age) of labor market participants. And inequality of opportunity is estimated as the part of between-group inequality that is attributable 
to circumstances, and obtained by estimating the "contribution" of these circumstances to the D-Index ${ }^{8}$.

We use two broad definitions of "opportunities" in the labor market. These definitions were chosen as a compromise between availability of information in the surveys and the extent to which each is amenable to interpretation as an "opportunity". The universe considered is all adults 18-64 years old in the labor force. The labor force includes individuals who are working, those without work but looking for one, and those without work and not looking for a job because they are discouraged from searching. An individual in this population is characterized as having an opportunity in two different ways: (a) having a job with defined set of characteristics such as 20 hours of work per week, tenure, or contracts; and (b) having suffered no event of economic distress or shock related to employment in the past one year. Economic distress is defined as a reported event of having collected unemployment insurance, experienced wage cuts, or worked at a job below qualification in the year prior to the survey. Individuals without opportunities are those who are unemployed but looking for a job, unemployed but not looking for a job due to discouragement and those who are employed but in jobs with characteristics inferior to the ones considered above.

In defining circumstances, we take into account characteristics that an individual is born into, which should not matter for access to the opportunity being considered. Guided by this principle and data availability, the circumstances we select are: gender of the individual, education of father, whether parents were affiliated to the communist party, and self-reported minority status. Gender and minority status are common types of circumstances considered in the literature; father's education is a proxy for socioeconomic background; and whether parents are affiliated to the communist party can be a proxy for social status in these countries.

In addition to circumstances, characteristics like education and age of the individual are included in the estimation exercise as they are common correlates of labor market variables and are generally used to determine returns to education and experience. When we go from measuring the overall level of between-group inequality to measuring inequality of opportunities in the labor market, we will have to isolate the contribution of circumstances to inequality from that of education and age. Finally, to facilitate comparisons across countries, the same set of circumstances and attributes and identical definitions of opportunities are used for all countries.

The correlation between circumstances and access to an opportunity (e.g. having a job with contract) can occur through two channels: the "direct" effect (e.g. belonging to a particular minority or gender group can affect the likelihood of getting a job just by virtue of these circumstances), and an "indirect effect" (circumstances can also influence the education of a person, which in turn influences the likelihood of getting a job). Our empirical strategy of isolating the contribution of circumstances to betweengroup inequality from that of education and age, is intended to measure the effect through the first (direct) channel and not the second ${ }^{9}$. The direct effect of circumstances in the labor market can be interpreted as inequality of opportunity that is produced by distortions in the labor market, distinct from those produced in earlier stages of life (prior to the individual's entry into the labor market). 


\subsection{Estimating the inequality index and the contribution of circumstances}

To decompose the D-index into the contributions of circumstances and characteristics to inequality, we apply the decomposition proposed by Shorrocks (2012), which is based on the Shapley value concept in cooperative games to distribute among the players the surplus produced by a coalition of cooperating players (see Hoyos and Narayan, 2011). The basic idea behind this decomposition is to measure how much the estimated D-Index would change when we add a circumstance or characteristic to different pre-existing sets of circumstances and characteristics. The change in inequality as a result of adding a circumstance or characteristic would be a reasonable indicator of the "contribution" of that variable to inequality of opportunities. Implementing this idea however needs to take into account the fact that since the variables (circumstances and characteristics) are correlated to each other, the change in the inequality measure obtained by "adding" a variable depends on the initial set or subset of variables to which it is added. Thus to identify the unique impact of adding a circumstance or characteristic to the measure, we consider all the changes that occur when the variable of interest is added to all possible subsets of pre-existing variables, and take the average of all these possible changes. (See Hoyos and Narayan, 2011 for details)

\subsection{Key limitations and caveats}

There are a number of limitations to our analysis of opportunities in the labor markets, some of which are important to highlight. The first has to do with the question of what constitutes an opportunity. What is ethically acceptable or desirable is generally dependent on the society's judgment. But we have no information about the quality of the jobs people have - having a "bad" job may not necessarily be an opportunity, especially when the bad job is a last resort against poverty and one that others who can afford to wait would rather not take.

The second caveat is related to the fact that "having a job" is an equilibrium phenomenon that obscures individual choices, including the possibility that individuals with certain circumstances can have a proclivity for certain types of jobs. Gender or parents' political affiliation, for example, may foster value systems and cultural norms that influence the choices embedded in the equilibrium outcome. Ideally, inequality of opportunity in labor market should be measured by the influence of circumstances on "employability" rather than the actual state of being employed. Nevertheless, employability would be hard to observe and measure in labor force surveys. Notwithstanding these caveats, if "having a job with certain characteristics (e.g. 20+ hours)" is considered to be a socially desirable state, as it is in most societies, our exercise with all its caveats is still informative, provided the results are interpreted carefully. Our definition of opportunity does take into account "discouragement", which refers to individuals not employed or looking for work just because they do not expect to find any. Such individuals are included in our universe and classified as equivalent to those who are in the labor force and do not have a job of the desired quality.

A second important issue is that of possible selection bias in labor force participation. The bias that can arise in a standard logit model - which is what we use - as a result of failing to properly control for this selection are well known. In our case, 
these biases would affect the inequality estimates and their decompositions. Incorporating standard econometric techniques to correct for selection bias turns out to be nontrivial in our approach ${ }^{10}$. For this reason, we opt for non parametric approaches in order to conduct robustness exercises for seven countries (see Additional file 1). We find that although selection is an issue, attempts to correct for it would increase the level of measured inequality, but not change the relative ranking of these seven countries in terms of the extent of inequality in their labor markets.

Finally, there is the issue of missing circumstances. In our analysis, we can only consider those circumstances that are measurable and available in the data. The set of these circumstances is only but a subset of the full set of circumstances that may matter for the opportunities we consider. If some of the missing variables are correlated with the ones that are included, as is likely to be the case, our predictions and therefore the D-Index are likely to have omitted variable bias. This is mitigated by the property of the D-Index that as more circumstances are added, its value can only increase. However, the fact that the estimated $\mathrm{D}$ is a lower bound of inequality between groups does not necessarily translate to a lower bound for the total contribution of circumstances to the D-index. In other words, if more (hitherto missing) circumstances were to be added, increasing the D-Index, the total estimated contributions of circumstances to the index will also increase in most cases, but not necessarily always.

\section{Results}

In this section we present our first set of results from the application of the HOI methodology to labor market outcomes in countries in the ECA region. The data we use is from the LiTS 2006. Between August and October 2006, a nationally representative sample of 1,000 households was interviewed in 29 countries: Albania, Armenia, Azerbaijan, Belarus, Bosnia and Herzegovina, Bulgaria, Croatia, Czech Republic, Estonia, Republic of Macedonia, Georgia, Hungary, Kazakhstan, Kyrgyz Republic, Latvia, Lithuania, Moldova, Mongolia, Montenegro, Poland, Romania, Russia, Serbia, Slovakia, Slovenia, Tajikistan, Turkey, Ukraine, and Uzbekistan. In order to gather information on the impact of the transition on individuals in the ECA region, data was collected from adults on personal information and family background, material well-being, life satisfaction and attitudes towards the new political and economic setting, and life history since the early nineties. We use the information on family background and labor market experience to compute the main indicators analyzed.

The coverage and the HOI for each of the labor market opportunities for a selection of ECA countries for one of the opportunities - the opportunity to hold a job with at least 20 hours a week - are presented in Table 1. The full results including the values for the D-index and the overall penalty for each opportunity are in Additional file 1. The first two columns in Table 1 show the overall coverage and the HOI for the opportunity to have 20 hours + employment. Recall that HOI is the inequality-adjusted coverage rate of each opportunity, where inequality is measured between groups differentiated by both circumstances and characteristics (education and age of individual). The gap between the coverage and HOI for each country and opportunity represents the "penalty" due to inequality between groups (the penalty is equal to the D-Index multiplied by the coverage). 
Table 1 Coverage, penalty, dissimilarity index and the human opportunity index for the opportunity to be in possession of a 20+ hours/week job

\begin{tabular}{|c|c|c|c|c|c|c|c|c|c|c|}
\hline \multirow[b]{2}{*}{ Country } & \multicolumn{2}{|c|}{$20+$ hrs/week } & \multicolumn{2}{|c|}{ No economic distress } & \multicolumn{2}{|c|}{$20+\mathrm{hrs} /$ week with contract } & \multicolumn{2}{|c|}{$20+\mathrm{hrs} /$ week with tenure } & \multicolumn{2}{|c|}{$\begin{array}{l}\text { Holds salaried job with contract or is self-employed } \\
\text { in professional occupation }\end{array}$} \\
\hline & $\mathrm{HOI}$ & Coverage & $\mathrm{HOI}$ & Coverage & $\mathrm{HOI}$ & Coverage & $\mathrm{HOI}$ & Coverage & $\mathrm{HOI}$ & Coverage \\
\hline Albania & 0.42 & 0.49 & 0.89 & 0.91 & 0.21 & 0.34 & 0.39 & 0.46 & 0.24 & 0.37 \\
\hline Belarus & 0.71 & 0.75 & 0.91 & 0.93 & 0.88 & 0.92 & 0.44 & 0.48 & 0.89 & 0.92 \\
\hline Bosnia & 0.53 & 0.57 & 0.85 & 0.88 & 0.53 & 0.59 & 0.49 & 0.53 & 0.54 & 0.60 \\
\hline Bulgaria & 0.67 & 0.73 & 0.86 & 0.89 & 0.71 & 0.77 & 0.58 & 0.65 & 0.72 & 0.78 \\
\hline Croatia & 0.66 & 0.70 & 0.83 & 0.85 & 0.77 & 0.82 & 0.59 & 0.64 & 0.77 & 0.82 \\
\hline Czech & 0.76 & 0.80 & 0.89 & 0.91 & 0.84 & 0.87 & 0.71 & 0.75 & 0.85 & 0.88 \\
\hline Macedonia & 0.51 & 0.56 & 0.84 & 0.86 & 0.45 & 0.53 & 0.45 & 0.50 & 0.47 & 0.55 \\
\hline Hungary & 0.66 & 0.70 & 0.83 & 0.86 & 0.58 & 0.63 & 0.62 & 0.66 & 0.59 & 0.64 \\
\hline Moldova & 0.53 & 0.58 & 0.88 & 0.91 & 0.45 & 0.55 & 0.49 & 0.54 & 0.45 & 0.55 \\
\hline Montenegro & 0.53 & 0.58 & 0.80 & 0.83 & 0.50 & 0.58 & 0.44 & 0.50 & 0.51 & 0.59 \\
\hline Poland & 0.59 & 0.63 & 0.87 & 0.89 & 0.70 & 0.74 & 0.56 & 0.60 & 0.71 & 0.75 \\
\hline Romania & 0.58 & 0.64 & 0.91 & 0.93 & 0.71 & 0.77 & 0.51 & 0.58 & 0.72 & 0.78 \\
\hline Serbia & 0.63 & 0.66 & 0.76 & 0.80 & 0.60 & 0.66 & 0.51 & 0.54 & 0.61 & 0.67 \\
\hline Slovakia & 0.71 & 0.75 & 0.85 & 0.87 & 0.78 & 0.83 & 0.65 & 0.70 & 0.79 & 0.83 \\
\hline Slovenia & 0.69 & 0.74 & 0.80 & 0.82 & 0.74 & 0.80 & 0.60 & 0.66 & 0.75 & 0.80 \\
\hline Turkey & 0.50 & 0.54 & 0.92 & 0.94 & 0.22 & 0.30 & 0.43 & 0.48 & 0.27 & 0.36 \\
\hline Ukraine & 0.60 & 0.64 & 0.87 & 0.88 & 0.68 & 0.71 & 0.52 & 0.57 & 0.69 & 0.73 \\
\hline Armenia & 0.24 & 0.30 & 0.87 & 0.89 & 0.26 & 0.34 & 0.22 & 0.27 & 0.26 & 0.34 \\
\hline Azerbaijan & 0.25 & 0.30 & 0.91 & 0.93 & 0.22 & 0.34 & 0.20 & 0.25 & 0.23 & 0.35 \\
\hline Estonia & 0.73 & 0.77 & 0.86 & 0.89 & 0.82 & 0.85 & 0.59 & 0.65 & 0.83 & 0.86 \\
\hline Georgia & 0.40 & 0.44 & 0.91 & 0.93 & 0.28 & 0.35 & 0.29 & 0.34 & 0.29 & 0.36 \\
\hline Kazakhstan & 0.65 & 0.69 & 0.85 & 0.87 & 0.66 & 0.73 & 0.57 & 0.61 & 0.67 & 0.74 \\
\hline Kyrgyz & 0.48 & 0.53 & 0.92 & 0.94 & 0.46 & 0.56 & 0.36 & 0.41 & 0.49 & 0.59 \\
\hline Latvia & 0.67 & 0.72 & 0.80 & 0.83 & 0.76 & 0.81 & 0.60 & 0.64 & 0.78 & 0.82 \\
\hline
\end{tabular}


Table 1 Coverage, penalty, dissimilarity index and the human opportunity index for the opportunity to be in possession of a $20+$ hours/week job (Continued)

\begin{tabular}{lllllllllll}
\hline Lithuania & 0.63 & 0.69 & 0.82 & 0.84 & 0.75 & 0.80 & 0.53 & 0.60 & 0.76 \\
\hline Mongolia & 0.59 & 0.64 & 0.92 & 0.94 & 0.56 & 0.64 & 0.48 & 0.52 & 0.50 \\
\hline Russia & 0.73 & 0.76 & 0.82 & 0.85 & 0.77 & 0.81 & 0.62 & 0.66 & 0.78 \\
\hline Tajikistan & 0.46 & 0.50 & 0.83 & 0.86 & 0.54 & 0.60 & 0.31 & 0.36 & 0.84 \\
\hline Uzbekistan & 0.53 & 0.59 & 0.81 & 0.83 & 0.58 & 0.65 & 0.44 & 0.50 & 0.62 \\
\hline Note Cove
\end{tabular}

Note: Coverage is the raw average of the proportion of those who are active in the labor market that hold a job with 20+ hrs/ week. HOl is the coverage discounted by the penalty for unequal distribution of these opportunities between the various circumstance groups. 
The opportunity labeled "no economic distress" is defined as not having suffered any event of economic distress or shock related to employment in the past one year. In order to see whether taking into account the quality of jobs, to the extent allowed by the data, makes a difference to the results, we impose some additional restrictions to our original definition of opportunity in the labor market. We start with the original indicator of having a job with more than 20 hours per week. In order to capture the stability aspect of the job in question, we first modify the definition of an "opportunity" to having a job with more than 20 hours/week and at least 6 months of tenure. Next, we define having any job with contract (regardless of hours worked) as the indicator of opportunity, where the sample of analysis consists of only the salaried workers and the unemployed and excludes the self-employed. Since salaried workers are a subgroup of all employed persons, we then broaden the indicator so that it can be defined for all workers: having a job that is either salaried with contract or being self-employed in a professional occupation.

There is a considerable variation in the access to these labor market opportunities across the countries in this region. Looking simply at coverage of the opportunity to hold a job that entails at least 20 hours of employment per week, for example, the average ranges from about 30 percent for countries like Armenia and Azerbaijan to 80 percent in Czech Republic. There is also variation across opportunities as should be expected because the very definitions of opportunities embody varying level of restrictiveness. What is interesting is the gap between the coverage and HOI and the differences in these gaps across countries. For example consider difference between coverage and HOI for the same opportunity for two different countries Russia and Albania. In Russia, the penalty is 0.03 while in Albania where the coverage itself is already low, the penalty for inequality is more than twice that for Russia. The fact that Albania does worse than Russia in this particular opportunity is clear enough from the coverage numbers. But a refinement that the HOI brings is that it enables us to see that that Albania would compare even more unfavorably if the distributional aspects of the opportunity were to be taken into account.

Next we present the share of the inequality (in each of the labor market indicators considered) that is attributable to circumstances, age and education. The shares are obtained using the Shapley decomposition of the index where the total contribution of is summed over the contributions of each of the four circumstances: gender, father's education, parent's political affiliation and self-reported minority status. For ease of exposition, we show this breakdown only for one opportunity here. Results of similar decompositions for the other opportunities are in Additional file 1.

From Table 2 it is apparent that the share of inequality attributable to circumstances is substantial in most cases, contributing to more than half of the overall inequality across all the countries. Another notable fact that emerges is that education also contributes a sizeable amount to the inequality as well. In some ways, this is not surprising because education, to the extent that it correlates with skills and employability, is and perhaps should be a big discriminant in the labor market. But note that educational attainment itself may be highly unequally distributed in any of these countries. This indirect effect of circumstances on labor market through education is not captured in this framework. Within circumstances, gender and father's education appear to make the largest contribution to the overall inequality of opportunity. 
Table 2 Contribution to the overall inequality (Shapley decomposition) of the opportunity to be in possession of a $20+$ hours/week job

Shapley decomposition (\% contribution to inequality)

\begin{tabular}{|c|c|c|c|c|c|c|c|}
\hline \multirow[b]{2}{*}{ Country } & \multicolumn{3}{|c|}{ Characteristics } & \multicolumn{4}{|c|}{ Within circumstances } \\
\hline & Age & Education & Circumstances & Gender & $\begin{array}{c}\text { Father's } \\
\text { education }\end{array}$ & $\begin{array}{c}\text { Parents' } \\
\text { politics }\end{array}$ & $\begin{array}{c}\text { Minority } \\
\text { status }\end{array}$ \\
\hline Albania & 13 & 42 & 46 & 32 & 8 & 0 & 5 \\
\hline Belarus & 2 & 24 & 74 & 47 & 20 & 0 & 7 \\
\hline Bosnia & 6 & 28 & 66 & 9 & 33 & 14 & 10 \\
\hline Bulgaria & 1 & 60 & 39 & 6 & 21 & 3 & 10 \\
\hline Croatia & 4 & 34 & 62 & 39 & 17 & 3 & 3 \\
\hline Czech & 2 & 55 & 43 & 10 & 16 & 12 & 5 \\
\hline Macedonia & 19 & 42 & 39 & 18 & 9 & 7 & 4 \\
\hline Hungary & 2 & 20 & 78 & 27 & 45 & 2 & 3 \\
\hline Moldova & 7 & 49 & 44 & 5 & 9 & 11 & 19 \\
\hline Montenegro & 12 & 52 & 36 & 4 & 20 & 2 & 10 \\
\hline Poland & 3 & 56 & 41 & 10 & 28 & 0 & 3 \\
\hline Romania & 12 & 53 & 36 & 14 & 12 & 0 & 10 \\
\hline Serbia & 1 & 13 & 86 & 43 & 21 & 21 & 1 \\
\hline Slovakia & 16 & 27 & 57 & 14 & 26 & 12 & 5 \\
\hline Slovenia & 5 & 20 & 75 & 25 & 34 & 3 & 12 \\
\hline Turkey & 0 & 15 & 85 & 72 & 11 & 0 & 2 \\
\hline Ukraine & 14 & 41 & 46 & 10 & 14 & 18 & 4 \\
\hline Armenia & 10 & 68 & 22 & 9 & 10 & 3 & 0 \\
\hline Azerbaijan & 15 & 26 & 59 & 49 & 6 & 4 & 0 \\
\hline Estonia & 8 & 48 & 43 & 8 & 27 & 5 & 3 \\
\hline Georgia & 8 & 12 & 80 & 27 & 49 & 0 & 3 \\
\hline Kazakhstan & 6 & 24 & 70 & 54 & 10 & 2 & 4 \\
\hline Kyrgyz & 13 & 26 & 60 & 9 & 16 & 19 & 17 \\
\hline Latvia & 6 & 35 & 59 & 45 & 10 & 2 & 2 \\
\hline Lithuania & 1 & 58 & 41 & 5 & 10 & 2 & 24 \\
\hline Mongolia & 5 & 39 & 56 & 17 & 28 & 4 & 7 \\
\hline Russia & 5 & 37 & 58 & 4 & 40 & 13 & 2 \\
\hline Tajikistan & 2 & 18 & 80 & 4 & 54 & 4 & 18 \\
\hline Uzbekistan & 6 & 16 & 78 & 65 & 9 & 2 & 3 \\
\hline
\end{tabular}

Note: The first three columns present the breakdown of the total inequality into components associated with age, education and circumstances. The next four columns further break down circumstances into shares contributed by gender, father's education, parents' politics and minority status.

\section{Validating our measure of inequality of opportunity}

While the results we have presented so far are informative in their own right, it is also useful to pause and think about what exactly we are capturing in our inequality measure and to try and determine whether it has sensible properties ${ }^{11}$. In this section we attempt to benchmark the calculated measure of inequality of opportunity with: (a) alternative measures of inequality, such as the Theil index (particularly the between group component of it) applied to continuous measures of outcome (household expenditures); (b) perceptions of life satisfaction and fairness. 


\subsection{Comparisons with Theil-L index for expenditures}

Our analysis of inequality of opportunity in the labor market so far is based on discrete outcomes. But the literature offers ways to analyze and decompose inequality of opportunity in continuous variables. We use one such method proposed and implemented by Ferreira et al. (2011) to assess the degree of inequality of opportunity in Turkey. The key question we want to ask is how our measure of the inequality of opportunity in the labor market - as defined by employment in certain types of jobs - compares with inequality of opportunity measures derived from income (or its proxies).

The LiTs surveys also contain a consumption module but these are considerably shorter than the standard household income and budget surveys. Comparisons of the consumption data from LiTS with expenditure data from extensive surveys in the same region have revealed substantial discrepancies in the first moment (mean) of the distributions, but concluded that they provide a similar ranking of households in the distribution (Zaidi et al. 2009). We use the Theil-L index of consumption as an inequality measure. The goal of this exercises is to decompose the relevant outcome (consumption) into a between component due to circumstances and a within component due to effort or luck (as in Ferreira et al., 2011) ${ }^{12}$. In order to decompose the Theil we estimate an equation of the consumption aggregate as a function of circumstances only. The Theil corresponds to the sum of means of the two constructed distributions. The relevant component of the Theil comes from the smoothed distribution: differences across the average advantages of types are due to inequality in opportunities and not effort. There are important methodological differences between the Theil index and the D-Indices presented in the previous section that we describe on the Additional file 1.

We compute the Theil index for household expenditures using the LiTS data for 29 countries. The decomposition of the Theil index into between and within components indicates a non-trivial amount of inequality in expenditure coming from the betweencomponent, which is our measure of inequality of opportunity (see Figure 1a). Although there are important methodological differences between Theil and D-Index, we find it reassuring that there is some positive cross-country correlation between the two measures (Figure 1b). But the components of each measure that relate to inequality of opportunity - the between-component of Theil and the contribution of circumstances -have little or no correlation (Figure 1c). Given the conceptual and methodological differences between the two types of measures, the lack of correlation is not surprising. From these results, we conclude that while the inequality indices per se have some correlation, the components of each measure that relate to inequality of opportunity (inequality attributable to circumstances) are best seen as complements of each other, addressing questions that are quite different.

\subsection{Comparisons with perceptions of life satisfaction and fairness}

To what extent do our measures of inequality in the labor market resonate with perceptions of fairness and satisfaction in society? We investigate this question in this section. Our objective is not so much to make a direct contribution to the vast literature on the relationship between measures of economic well -being (absolute or relative) and subjective measures such as happiness, but to examine if our measured inequality 


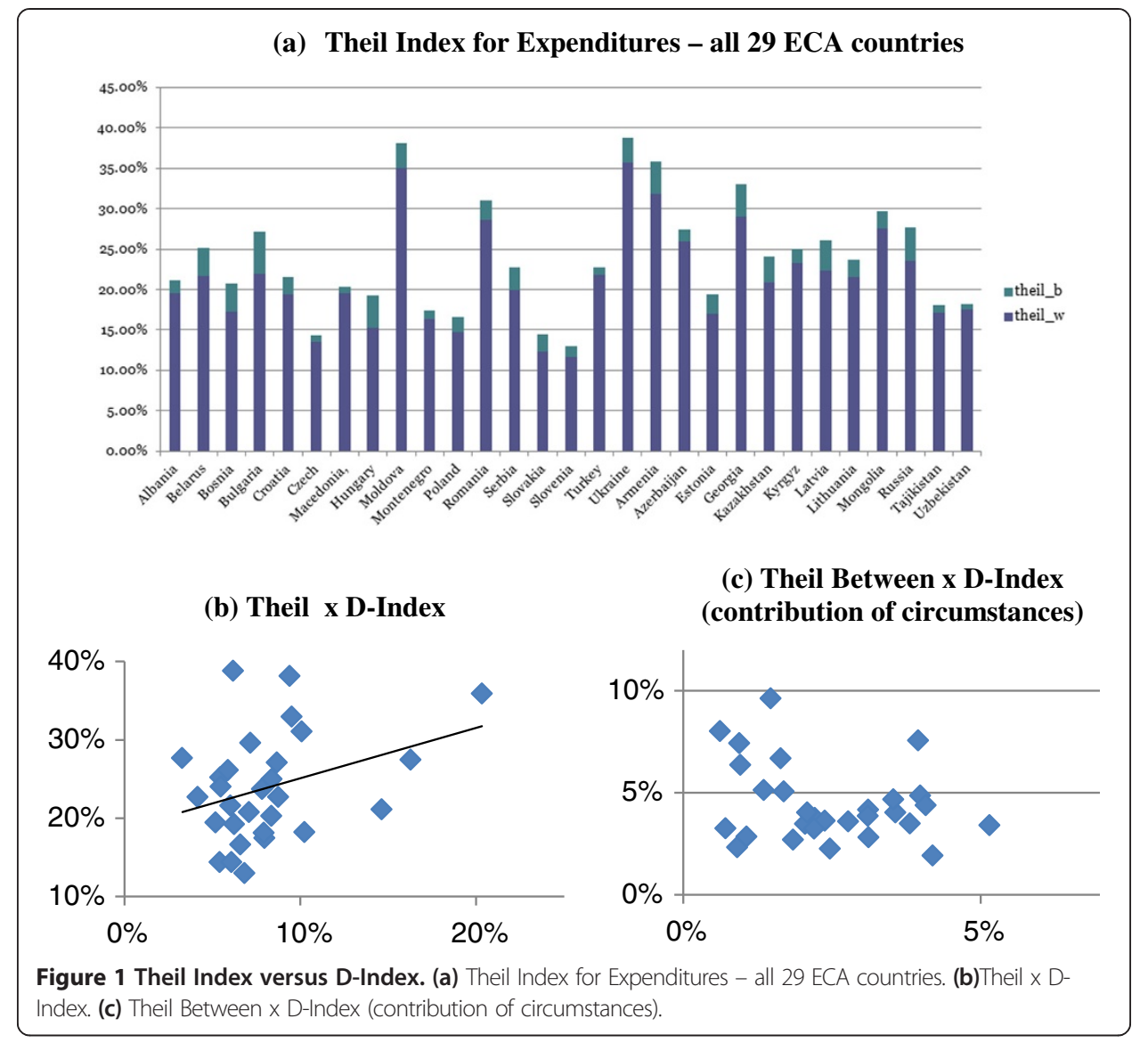

of opportunity relates to these perceptions in a sensible way. In that sense, our work in this area should be viewed at best as a crude validation exercise for our inequality measures discussed in the earlier sections. In order to be a validation exercise, however, one needs priors - preferably grounded in theory - on what the expected relationship between any measure of inequality of opportunity and perceptions of fairness and life satisfaction should be. Although the idea of fairness is not explicitly formalized in our framework, it is central to the idea of inequality of opportunity. If equality is a legitimate social goal, then inequality due to circumstances would be associated with unfairness while any inequality coming from differential efforts would constitute "fair play".

Theoretically, it is less clear what the relationship between life satisfaction or happiness and inequality of opportunity should be. For the case of inequality in outcomes, there are two main competing hypotheses that lead to opposite predictions on the happiness-inequality relationship. The first is the 'tunnel effect' proposed by Hirschman and Rothschild (1973), which suggests that higher inequality signals higher potential for future economic mobility and hence leads to greater life satisfaction today. The second hypothesis forwarded by Runciman (1966) is about relative deprivation: the higher the current economic inequality, the higher the relative deprivation and hence lower the current life satisfaction. The ambiguity about which of these two opposing effects dominates is reflected in the fact that the large body of empirical work that has attempted to test the inequality aversion hypothesis remains largely inconclusive (see Frey and Stutzer, 2002; Stevenson and Wolfers 2008; Verme 2011 among others). 
What we consider here however is inequality of opportunities, which is distinct from inequality of outcomes. This distinction becomes particularly relevant in this context because while the Hirschman/Rothschild mechanism of higher inequality signaling higher potential mobility may be plausible for outcome inequality, it is hard to imagine the same holding true for inequality of opportunities. In fact, a significant fraction of the society - particularly those belonging to the disadvantaged types - would see rising inequality of opportunity as diminishing their chances of economic mobility. By this token, it can be argued that the relationship between inequality of opportunity - unlike the case of inequality of outcomes such as income or expenditure - on perceptions of life satisfaction should be negative.

We examine this issue empirically using measures of perceptions from the LiTS data. We use two questions to obtain our measures of life satisfaction and perception of fairness. The first is a rating of the statement "All things considered, I am satisfied with my life now". Individuals reporting to agree or to strongly agree are deemed to be satisfied as opposed to those answering strongly disagree, disagree, or neither disagree nor agree. The second is "In your opinion, which of the factors in this list is the most important to succeed in life in this country now?" Individuals answering factors such as effort, hard work, intelligence and skill are deemed to believe in fairness of the society they live in, while political connections, corruption ties or other reasons indicate skepticism about fairness.

We estimate logit models using life satisfaction and perceptions of fairness as dependent variables, and including different measures of inequality at the country level - Gini of consumption, various D-indices and Theil index (between and within components) - as regressors. The regressions are of the following form,

$$
y_{i j k}=\alpha+\delta I N E Q U A L I T Y_{k}+\gamma^{\prime} X_{i j k}+\theta^{\prime} Z_{i j k}+\rho D_{k}+\varepsilon_{i j k}
$$

Where $y_{i j k}$ represents the expressed life satisfaction or perception of fairness of individual $i$ in region $j$ in country $k . X$ represents a vector of individual level characteristics that could potentially confound our inference of the coefficient on the inequality measure and includes gender, employment status (whether one holds a job with 20+ hours of work), age, squared age, educational level, education of the parents, self-reported minority status, parents' participation in/affiliation to the communist party, religious affiliation and household expenditure. $Z$ represents a vector of additional variables such as expressed opinions regarding democracy, the market economy, the need to reduce inequality through government action, financial situation in the country and doing better than others in life - all of which are likely to be related to an individual's "core beliefs" that affect perceptions of fairness and satisfaction in life. We include country level expenditure and dummy variables for classes of country (in some specifications), $D_{k}$ to take into account the level of development or average well-being of a country ${ }^{13}$. Since the inequality indices themselves can be highly correlated with each other, they are added one at a time in the regressions.

The benefit of including country fixed effects has to be traded off against the multicollinearity that this would induce with country level measures of inequality. Multicollinearity inflates the variance making our parameter estimates imprecise. Alternatively, clustering the standard errors at country geographical levels can help correct 
for possible correlation of beliefs within each country, region or locality. We define clusters at the regional level within each country, giving us a total of 350 cluster units (for 29,000 observations) and include those results as a robustness check.

The main results are presented in Table 3. The goal here is to estimate the partial correlations on the key variables of interest (the inequality measures) and not to examine the causal determinants of life satisfaction or perceptions of fairness in the ECA region. In general, there appears to be a negative association between country-level measures of inequality on the one hand and measures of life satisfaction and perception of fairness in society on the other hand. This relationship is robust to the inclusion of personal characteristics of the respondents as well as other beliefs about their society, economy and individual self-assessed relative socio-economic position vis-à-vis others in their reference group. The relationship between life satisfaction and inequality indices is also robust to clustering of standard errors at the regional level within each country and inclusion of country class dummies. The relationship between perception of fairness and inequality indices is less robust, as most of the coefficients on inequality indices turn not statistically significant with clustering of standard errors and/or inclusion of country class dummies ${ }^{14}$.

How do the inequality measures perform in these regressions, relative to each other? Among all indices, the between component of Theil has by far the highest partial correlation with life satisfaction and perception of fairness - the correlation with perception of fairness is significant even with clustering of standard errors and country class dummies, when all other inequality measures become insignificant. The Gini of consumption, the within component of Theil index and the three D-Indices (for three types of job opportunities) all have statistically significant and negative partial correlations with life satisfaction. The D-Indices also have significant correlations with perception of fairness (except with clustering and country class dummies) whereas the Gini and the within component of Theil do not.

The results for the between and within components of the Theil Index are particularly interesting. When they are both included in the regressions, higher between-group inequality - a measure of inequality of opportunity - is associated with lower life satisfaction and perception of fairness in the society. And higher within-group inequality the component of inequality that can be attributed to unobserved effort or luck - is also associated with lower life satisfaction, but higher perception of fairness. When the between and within components of Theil are added one at a time in the regressions, the former has significant and negative correlation with life satisfaction and perception of fairness, while the latter is correlated with only life satisfaction. Moreover, the between component of Theil and the D-Indices have consistently better correlation with perception of fairness than Gini of income.

Thus on the whole, people's perceptions of fairness seem to be inversely correlated with the extent of inequality of opportunity for a country, as measured by the betweencomponent of the Theil Index. In contrast, inequality within types (which is not attributable to circumstances) and overall inequality as measured by Gini coefficients do not have significant correlation with perceptions of fairness. To the extent that inequality of opportunity is fundamentally about individuals in society receiving a fair shot (or equal chance) of achieving success, the consistency between our measures and perceptions is noteworthy. Particularly, for life satisfaction and perception of fairness alike, 
Table 3 Partial correlations of life satisfaction and perceptions of fairness with various measures of inequality

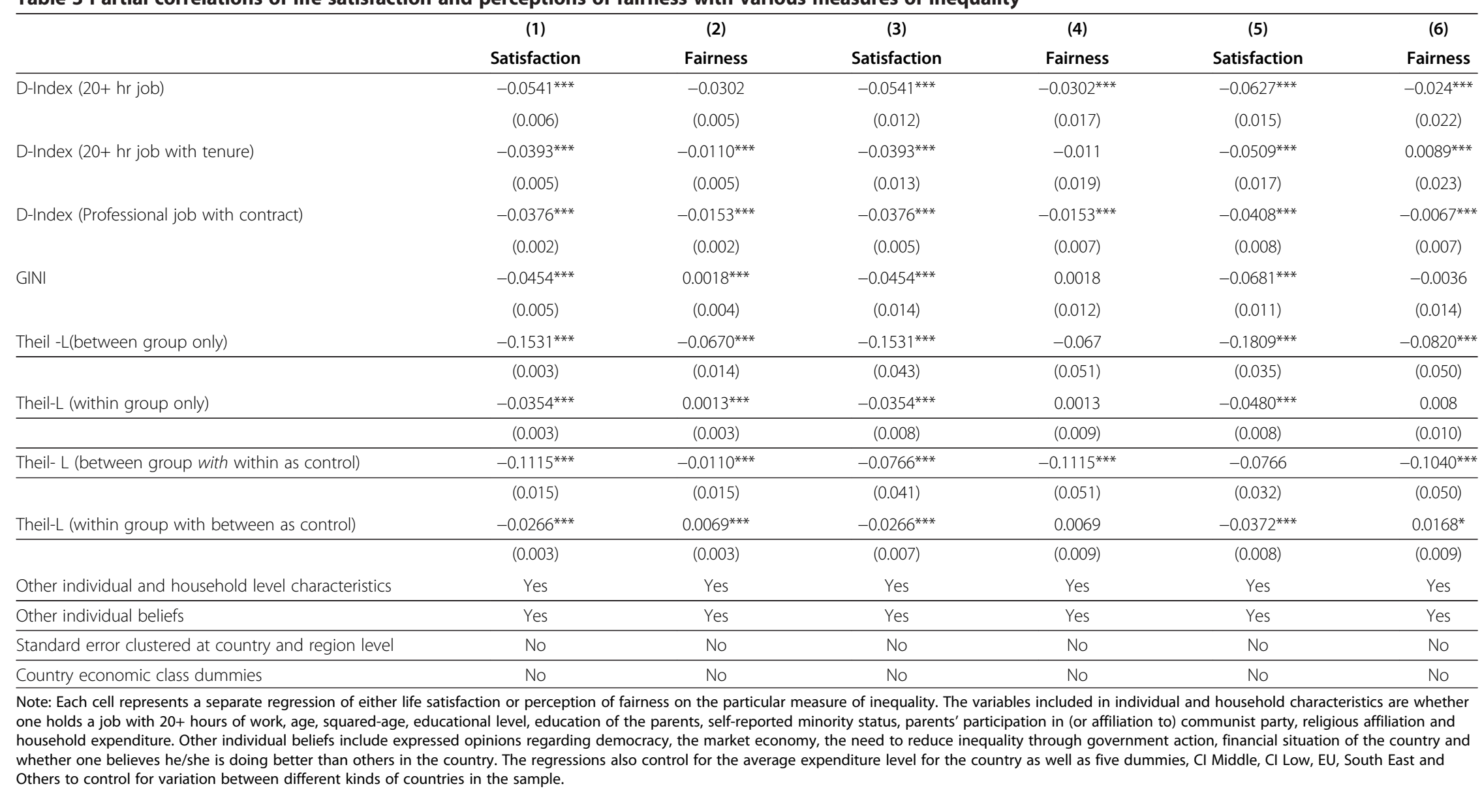


inequality between groups differentiated by circumstances seems to matter much more than other components (or overall level) of inequality.

The between-component of the Theil Index has intuitive appeal as a broad measure of inequality of economic opportunities. The uneven correlation of the D-Indices for jobs with fairness is not surprising, given that the perception indicators we have used relate to "life" in general and not just employment. A better "test" of the D-Indices we use would have been a question that asks respondents to rate fairness in job opportunities which is unavailable from LiTS.

Next, we examine more closely the role of other potentially confounding factors in the regression exercises. In particular, we investigate the hypothesis that instead of having isolated individual beliefs about any one issue, respondents have a body of beliefs that would guide how they generally feel about political and economic situations. We partition our sample into different groups according to self-assessments of relative economic success and political tendencies and re-examine the fairness-inequality relationship within these partitions.

The results of this exercise presented in Table 4 offer some interesting insights. First, these results suggest that the fairness-inequality relationships do vary a lot from one partition of the sample to another. Second, although hard to generalize, these results indicate that the negative correlation between inequality of opportunity measures and perceptions of fairness tend to be stronger for the subsamples of respondents who did worse than their peers, favor redistribution, are not satisfied with the economy, or distrust market economies - all of which seem to be consistent with intuition.

\section{Conclusion}

In this paper we extend the HOI methodology to study inequality of opportunity in labor markets in a number of countries in the Europe and Central Asia region. In addition to computing the absolute magnitude of these inequalities, we also decompose the inequality into contributions related to exogenous circumstances such as gender, parents' education, parents' affiliation to the dominant political party and self-reported minority status on the one hand and characteristics such as education and age on the other. To our knowledge, this is the first attempt to compute inequality of opportunity in labor markets in a discrete setting (i.e., where the opportunity relates to a binary outcome variable). Our findings show substantial inequality of opportunity in the labor market, estimated as the contribution of circumstances (that an individual was born into) to between-group inequality in employment status in a number of countries in the ECA region. There is a high degree of heterogeneity across countries in the circumstances that matter the most for inequality, with gender, parental education and selfreported minority status all mattering to varying degrees in different countries.

Second, we make use of an extensive module on perceptions and attitudes available in our survey to check the degree to which our measures of inequality resonate with expressed satisfaction with life and perceptions of overall fairness in a country. We find that our measures of inequality resonate fairly well with expressed life satisfaction in expected ways: higher inequality is associated with lower life satisfaction. Interestingly, the component of the Theil measure that is a reasonable measure of inequality of opportunity correlates the best in the expected direction with individual perceptions of 
Table 4 Perceptions of fairness and inequality in various subsamples

\begin{tabular}{|c|c|c|c|c|c|c|c|c|c|c|}
\hline & $\begin{array}{l}\text { Did better } \\
\text { than peers }\end{array}$ & $\begin{array}{l}\text { Did worse } \\
\text { than peers }\end{array}$ & $\begin{array}{c}\text { Favors } \\
\text { redistribution }\end{array}$ & $\begin{array}{l}\text { Does not favor } \\
\text { redistribution }\end{array}$ & $\begin{array}{l}\text { Satisfied with } \\
\text { the economy }\end{array}$ & $\begin{array}{l}\text { Not satisfied with } \\
\text { the economy }\end{array}$ & $\begin{array}{l}\text { Markets } \\
\text { are better }\end{array}$ & $\begin{array}{l}\text { Markets } \\
\text { are worse }\end{array}$ & $\begin{array}{l}\text { Democracy } \\
\text { is better }\end{array}$ & $\begin{array}{l}\text { Democracy } \\
\text { is worse }\end{array}$ \\
\hline & Fairness & Fairness & Fairness & Fairness & Fairness & Fairness & Fairness & Fairness & Fairness & Fairness \\
\hline \multirow{2}{*}{ Theil-L (within group) } & -0.008 & 0.004 & 0.003 & -0.009 & $-0.023^{* * *}$ & $0.010^{* * * *}$ & $-0.027^{* * *}$ & $0.018^{* * *}$ & $-0.014^{* * *}$ & $0.020^{* * *}$ \\
\hline & $(0.007)$ & $(0.004)$ & 0.000 & $(0.008)$ & $(0.009)$ & $(0.003)$ & $(0.005)$ & $(0.004)$ & $(0.004)$ & $(0.005)$ \\
\hline \multirow{2}{*}{ Theil-L (between group) } & $-0.095^{* * *}$ & $-0.094^{* * *}$ & $-0.089^{* * *}$ & $-0.115^{* * *}$ & -0.062 & $-0.087^{* * *}$ & $-0.042^{* * *}$ & $-0.106^{* * *}$ & $-0.088^{* * *}$ & $-0.088^{* * *}$ \\
\hline & $(0.032)$ & $(0.017)$ & 0.000 & $(0.038)$ & $(0.040)$ & $(0.016)$ & $(0.025)$ & $(0.018)$ & $(0.021)$ & $(0.021)$ \\
\hline \multirow{2}{*}{$\begin{array}{l}\text { D-Index ( } 20+\text { hrs of work) } \\
\text { [Share of circumstances] }\end{array}$} & $-0.023^{*}$ & $-0.033^{* * *}$ & $-0.038^{* * *}$ & 0.001 & $-0.039^{* * *}$ & $-0.031^{* * *}$ & $-0.058^{* * *}$ & $-0.023^{* * *}$ & $-0.039^{* * *}$ & $-0.031^{* * *}$ \\
\hline & $(0.012)$ & $(0.005)$ & 0.000 & $(0.013)$ & $(0.011)$ & $(0.006)$ & $(0.008)$ & $(0.006)$ & $(0.007)$ & $(0.007)$ \\
\hline
\end{tabular}

Note: Each cell represents a separate regression of either perception of fairness on the particular measure of inequality. The variables included in individual and household characteristics are whether one holds a job with $20+$ hours of work, age, squared-age, educational level, education of the parents, self-reported minority status, parents' participation in (or affiliation to) communist party, religious affiliation and household expenditure. Other individual beliefs include expressed opinions regarding democracy, the market economy, the need to reduce inequality through government action, financial situation of the country and whether one believes he/she is doing better than others in the country. The regressions also control for the average expenditure level for the country as well as five dummies, CI Middle, CI Low, EU, South East and Others to control for variation between different kinds of countries in the sample. 
fairness, compared to other measures of inequality. The correlation of the various HOI-based indices with perception of fairness is significant in some cases but unstable, which (we hypothesize) may be related to the perception questions being much broader than the relatively narrow area of job opportunities these indices are concerned with. In this context, the fact that the between-group component of the Theil measure, which is about income inequality measured across the entire sample, correlates more closely to broad perceptions about fairness in life, is consistent with our initial expectations. Most of our measures also seem to be better correlated than the Gini of consumption with perceptions of life satisfaction and fairness. Thus the evidence appears to be consistent with the hypothesis that inequality between groups (including inequality attributable to circumstances) matters more for perceptions than overall inequality.

\section{Endnotes}

${ }^{1}$ See Roemer (1993) for a review of the proposals by different authors that attempt to equalize opportunities, rather than outcomes.

${ }^{2}$ These include Bourguignon et al. (2007); Van der Gaer (1993); Lefranc et al. (2008) and Ferreira et al. (2011).

${ }^{3}$ The process involves a transformation function, which depends on individual, social, and contextual (institutional) aspects. A larger set of options ("life plans" or combinations of functionings) in the capability set implies more "effective freedom" (see Basu and Lopez-Calva, 2010 and Sen, 2001).

${ }^{4} \mathrm{~A}$ "circumstance group" is a group of children that share the same circumstances.

${ }^{5}$ See Barros et al. (2010) for the derivations of the important properties of the dissimilarity index.

${ }^{6}$ See Barros et al. (2010) for a proof of the "lower bound" property of the D-Index.

${ }^{7}$ Ideally we would want to condition for an individual's experience in the labor market. But since that information is not available in the surveys, we use the individual's age as a proxy for experience, as is standard in the literature.

${ }^{8}$ Note that the lower bound property of the D-Index referred to earlier (the fact that the index will increase in value if the list of circumstances and characteristics were to be expanded) does not imply the same for our measure of inequality of opportunity here, namely the contribution of circumstances to the D-Index. Therefore, we cannot claim that inequality of opportunity as we measure it is the lower bound of the "true" inequality of opportunity if omitted circumstances and/or characteristics were taken into account.

${ }^{9}$ Estimating the "indirect" channel, the effect of circumstances through education, would be difficult because education depends on a host of factors other than the circumstances for which we have information. Moreover, excluding the impact of circumstances through education is justified because we are interested in measuring the extent to which inequality in the labor market is attributable to circumstances. While circumstances may very well have influenced educational attainment, these effects would have occurred at a much earlier stage of life (primarily in childhood), and therefore do not reflect inequality of opportunities specific to the labor market.

${ }^{10}$ Since our decomposition method involves running multiple configurations of the model with all possible subsets of covariates, incorporating a first-stage selection model 
necessarily implies that every configuration of the model has to be run using the 2-stage selection correction. This approach would be computationally intensive and unlikely to converge in all cases.

${ }^{11}$ Note that the results presented so far on the quantification of inequality of opportunity in the various labor market related opportunities for these countries is already very rich. In fact the analysis of differences in opportunities and why these opportunities are more or less correlated to the various circumstances between any two sets of countries in this sample could be an interesting exercise that may yield meaningful insights for policy. But in this paper, we eschew going that route mainly because our focus is more on the methodological side: we want to demonstrate this method in action and perform some checks on how meaningful the results might be.

${ }^{12}$ Foster and Shneyerov (2000) show that when the set of inequality indices under consideration is restricted to those that use the arithmetic mean as the reference consumption, the mean logarithmic deviation is the single inequality measure that satisfy the Pigou-Dalton transfer axiom and is path-independent decomposable.

${ }^{13}$ Country classes are CI Middle, CI Low, EU, South East, and Other.

${ }^{14}$ Since we focus on correlations, we are less worried to find low predictive power in the model specification: the R-squared of full regressions are around 0.20 and 0.05 for measures of satisfaction and perceptions of fairness respectively. See Additional file 1 for complete regression results with one of the inequality measures (D-Index for jobs $>20$ hours of work). Results for other regressions are similar and available upon request.

Competing interest

The IZA Journal of Labor and Development is committed to the IZA Guiding Principles of Research Integrity. The authors declare that they have observed these principles.

\section{Acknowlegments}

This work was done as a background paper for the World Development Report on Jobs (2013) and for regional studies in the ECA region. We have benefited from comments and suggestions provided by Dena Ringold, Carolina Sanchez-Paramo, Francisco Ferreira, Jaime Saavedra, Luis-Felipe Lopez-Calva and several participants of the Second World Bank Conference on Equity. We would also like to thank one anonymous referee for very useful comments. All remaining errors are our own.

Responsible editor: Hartmut Lehmann

Received: 14 November 2012 Accepted: 5 July 2013

Published: 15 Aug 2013

\section{Additional file}

Additional file 1 Appendix A. The Issue of Selection. Appendix B. Full results. Appendix C. Comparison between the Theil index and the HOI. Appendix D. Relationship of life satisfaction and perceptions of fairness with inequality of opportunity in the labor market (opportunity of having a $20 \mathrm{~h}+$ job).

\section{References}

Arneson R (1989) Equality of opportunity for welfare. Philos Stud 56:77-93

Arneson R (1990) Liberalism, distributive subjectivism, and equal opportunity for welfare. Philosophy \& Public Affairs 19(2):158-194

Barros R, Ferreira F, Molinas Vega J, Saavedra J (2009) Measuring inequality of opportunities in Latin American and the Caribbean. The International Bank for Reconstruction and Development. The World Bank, Washington, DC

Barros R, Molina Vega J, Saavedra J (2010) Measuring progress toward basic opportunities for All. Brazilian Review of Econometrics 30(2). Rio de Janeiro, Brazil

Basu K, Lopez-Calva L (2010) Functionings and capabilities. In: Arrow K, Sen A, Suzumura K (eds) Handbook of social choice and welfare. Elsevier Science B.V. North Holland

Betts J, Roemer J (2003) Equalizing educational opportunity through educational finance reform. Working Papers 998 University of California, Davis, Department of Economics 
Bourguignon F, Ferreira F, Menendez M (2007) Inequality of opportunity in Brazil. Review of Income and Wealth 53(4):585-619

Campos N, Jolliffe D (2007) Earnings, schooling, and economic reform: econometric evidence from Hungary (1986-2004). The World Bank Economic Review 21(3):509-526

Cogneau D, Mesplé Somps S (2008) Inequality of opportunity for income in five countries of Africa. In: Bishop J, Zheng $B$ (eds) Inequality and opportunity: papers from the second Ecineq society meeting, Research on Economic Inequality, Vol. 16th edition. Emerald Group Publishing Ltd, United Kingdom

Cohen G (1989) On the currency of egalitarian justice. Ethics 99:906-944

DiNardo J, Fortin N, Lemieux T (1996) Labor market institutions and the distribution of wages, 1973-1992: a semiparametric approach. Econometrica 64(5):1001-1044

Dworkin R (1981) What is equality? part I: equality of welfare; part 2: equality of resources. Philosophy and Public Affairs 10:185-246. 283-345

Ferreira F, Gignoux J (2011) The measurement of educational inequality achievement and opportunity. Policy Research Working Paper 5873. The World Bank, Washington, DC

Ferreira F, Gignoux J, Aran M (2011) Measuring inequality of opportunity with imperfect data: the case of Turkey. J Econ Inequal 9(4):651-680

Foster J, Shneyerov A (2000) Path independent inequality measures. Journal of Economic Theory 91:199-222

Frey B, Stutzer A (2002) What can economists learn from happiness research? J Econ Lit 40(2):402-435

Hild M, Voorhoeve A (2004) Equality of opportunity and opportunity dominance. Econ Philos 20:117-145

Hirschman A, Rothschild M (1973) The changing tolerance for income inequality in the course of economic development. Quarterly Journal of Economic 87(4):544-566

Hoyos A, Narayan A (2011) Inequality of opportunities among children: how much does gender matter? Background Paper for WDR 2012, Washington, DC. Manuscript

Lefranc A, Pistolesi N, Trannoy A (2008) Inequality of opportunities vs inequality of outcomes: are western societies alike? Review of Income and Wealth 54(4):513-546

Nozick R (1974) Anarchy, State and Utopia. Basic Books, New York, p 1974

Ooghe E, Schokkaert E, Van de Gaer D (2007) Equality of opportunity versus equality of opportunity sets. Social Choice and Welfare 28:383-390

Rawls J (1971) A theory of justice. The Belknap Press of Harvard University Press, Harvard University

Roemer J (1993) A pragmatic theory of responsibility for the egalitarian planner. Philosophy \& Public Affairs 22(2):146-166

Roemer J (1998) Equality of opportunity. Harvard University Press, Cambridge MA

Runciman W (1966) Relative deprivation and social justice. Reports of the Institute of Community Studies. Routledge and Kegan Paul, London, Boston and Henley

Sen A (1979) Utilitarianism and welfarism. J Philos LXXVI:463-489

Sen A (1985) Well-being, agency, and freedom: the Dewey lectures 1984. J Philos 82:169-221

Sen A (2001) Development as freedom. Oxford University Press, Oxford

Shorrocks (2012) Decomposition procedures for distributional analysis: a unified framework based on the Shapley value. J Econ Inequal 11(1):99-126. Springer Link. Published Online on January 2012

Stevenson B, Wolfers J (2008) Happiness Inequality in the United States. The Journal of Legal Studies, University of Chicago Press 37(\$2):S33-S79

Van der Gaer D (1993) "Equality of opportunity and investment in human capital", PhD dissertation. Catholic University of Leuven, Leuven

Verme P (2011) Life satisfaction and income inequality. World Bank Policy Research Working Paper \# 5574, Washington, DC World Bank (2006) World development report 2006: equity and development. The World Bank, Washington, DC

Zaidi S, Alam A, Mitra P, Sundaram R (2009) Satisfaction with life and service delivery in eastern Europe and the former soviet union some insights from the 2006 life in transition. The World Bank, Washington, DC

10.1186/2193-9020-2-7

Cite this article as: Abras et al:: Inequality of opportunities in the labor market: evidence from life in transition surveys in Europe and Central Asia. IZA Journal of Labor \& Development 2013, 2:7

\section{Submit your manuscript to a SpringerOpen ${ }^{\circ}$ journal and benefit from:}

- Convenient online submission

- Rigorous peer review

- Immediate publication on acceptance

- Open access: articles freely available online

- High visibility within the field

Retaining the copyright to your article

Submit your next manuscript at $\boldsymbol{\sim}$ springeropen.com 